\title{
Computed Tomography
}

National Cancer Institute

\section{Source}

National Cancer Institute. Computed Tomography. NCI Thesaurus. Code C17204.

A method of examining structures within the body by scanning them with $\mathrm{X}$ rays and using a computer to construct a series of cross-sectional scans along a single axis. 